\title{
Chemistry and Recycling Technology of Used Motor Oil
}

\section{KULASH K. SYRMANOVA ${ }^{1,2 *}$, ANASTASSIYAY. KOVALEVA ${ }^{1}$, ZHANAT B. KALDYBEKOVA ${ }^{1}$, NURZHANY. BOTABAYEV ${ }^{1}$, YERSULTANT. BOTASHEV ${ }^{1}$ and BORISY. BELOBORODOV ${ }^{1}$}

\author{
${ }^{1}$ Auezov South Kazakhstan State University, Kazakhstan, 160012, Shymkent, Tauke Khan av., 5, Kazakhstan. \\ 2"MIRAS” University, Kazakhstan, 160012, Shymkent, Ilyaev st., 5, Kazakhstan. \\ ${ }^{*}$ Corresponding author E-mail: syrmanova.kulash@mail.ru
}

http://dx.doi.org/10.13005/ojc/330665

(Received: September 28, 2017; Accepted: October 20, 2017)

\begin{abstract}
This article is devoted to the development of complex purification technology of used motor oil, its scientific and technological foundations formulations, including: determination the nature of contamination in used motor oil, research the ability of ultrasonic irradiation process to decontaminate of used motor oil, determination and optimization of the factors, that may affect feasibility and efficiency of the proposed method, research of the nature adsorbents (local origin) vermiculite influence on the efficiency of the used motor oil purification process from the unwanted components and to identify the optimal characteristics of materials. The estimated theoretical value of the work consists of integrated research of the regularities of unwanted components destruction by ultrasonic irradiation and adsorption and compare their effectiveness with foreign analogs, definition of the thermodynamics and kinetics of the adsorption process.
\end{abstract}

Keywords: Used motor oil, Vermiculite, Ultrasonic irradiation, Adsorption, Quality improvement, Pollution, Contamination.

\section{INTRODUCTION}

Used motor oil can be considered as an integral part of mechanisms and structural materials. At the end of service life, significant amount of waste lubricants are produced, which are currently one of the main type of technogenic wastes that have a very negative impact on the environment - atmosphere, soil and water ${ }^{1}$.

About $30 \%$ of lubricants are irretrievably lost during the operation of equipment: it burns in engines, evaporates, spills, washed away, etc. The remaining part is undergone to severe changes under the influence of operating conditions and must be removed from the machinery.

Despite the fact that waste lubricants represent a significant environmental hazard, they are valuable secondary stock and must be collected and utilized. This is a very complex process organizationally and still remains a serious problem².

Under the aging of motor oil is implied oxidation, contamination by the products of combustion of fuel and foreign impurities, as well as products of decomposition of additives during 
operation. Used motor oil often contains metals (usually as the result of the engine or bearing wear, or the inclusion of these metals in oil additives), chlorinated hydrocarbons and other organic compounds, including a lot of that are listed as priority pollutants. The presence of such toxic organic substances as benzene or naphthalene is usually associated with the oil formulation itself ${ }^{3,4}$.

It is important to notice that motor oil does not wear out, it becomes contaminated after a cycle of use. A proper treatment technology allows to remove priority pollutants (polyaromatic hydrocarbons, toxic metals, chlorinated hydrocarbons) from used oil, so used motor oil can be re-refined to base lubricating oil, processed into fuel oil or applied as a stocks for petroleum-based production.

Some used motor oils have the high contamination level and it increases the difficulties in the operations and generates hazardous byproducts as secondary pollutants. A large amount of the recycled used oil is combusted for energy utilization often creating air pollution problems ${ }^{5}$.

Nowadays in Kazakhstan there is no unified centralized system for collecting, regenerating or disposing of used lubricants, organizationally and legally approved, and having unified requirements for the received products.

In addition, there are no objective and generally accepted criteria for the aging of motor oils. The increase of the lubricants service life, which is economically advantageous, in most cases leads to the accumulation of environmentally hazardous products in them, which complicate the utilization processes $^{6}$.

Treatment and regeneration of used motor oils is extremely important, due to the high cost and in some cases the environmental hazard of such products (polychlorinated biphenyls, phosphoric acid esters, alkylbenzenes). Regeneration involves the restoration of the quality of the lubricant to a level comparable to the initial. Modern schemes of regeneration of wasted motor oils used in developed countries include physical and physicochemical processes - coagulation, sulfuric acid purification and adsorptive purification by synthetic or natural sorbents (bentonites, clays) ${ }^{7,8}$.

\section{EXPERIMENTAL}

Ultrasonic treatment is proposed partially remove toxic compounds from the used motor oil. Target contaminants that it is necessary to remove from the oil are: heavy metals, chlorinated hydrocarbons, benzene, toluene, ethylbenzene, xylenes, polyaromatic compounds ${ }^{9}$.

Ultrasonic irradiation is widely used in environmental cleaning technologies to degrade many toxic compounds in contaminated soils and waters. It was also proved that it has a positive effect on upgrading and recovery of fossil fuel. Free radical chain reaction is supposed to be the dominant reaction to cause the effects in these systems. The ultrasonic irradiation has the ability to initiate and enhance the free radical formation from hydrocarbons, so it could be assumed that ultrasonic irradiation would effectively remove or degrade harmful substances from used oil. In the case of technically and economically proven effect, the chemical-aided ultrasonic irradiation process could be used not only as the pretreatment step for used motor oil treatment ${ }^{10}$.

The adsorption purification is also an attractive special method to improve the quality of used motor oil, allowing at the same time to reduce the content of sulfur, nitrogen and polyaromatic compounds in fuel to meet modern quality standards. The optimum implementation of the process is a selective adsorption treatment, carried out under mild conditions at moderate temperature and atmospheric pressure. The advantages of this method include high efficiency, the ability to carry out the process without the participation of molecular hydrogen under relatively mild conditions, simplicity of technology, equipment, low capital and operating costs, as well as safety.

Vermiculite is going to be counted as an absorbent. Vermiculite is a hydrous phyllosilicate mineral. It undergoes significant expansion when heated. Exfoliation occurs when the mineral is heated sufficiently, and the effect is routinely produced in commercial furnaces. Vermiculite is formed by weathering or hydrothermal of biotite or phlogopite. In Kazakhstan "Kulantauskoe" deposit of vermiculite is located in Tyulkubas district of South Kazakhstan region. 


\section{RESULTS AND DISCUSSION}

The possibility of reducing the content of aromatic and polyaromatic hydrocarbons in engine oils by using ultrasonic radiation was researched. Two different samples of used engine oil were studied, as well as two unused engine oil samples for comparison were also researched. The marking and description of the samples are shown in Table 1.

Table. 1: Characteristics of the samples' test of engine oil

\begin{tabular}{lll}
\hline $\begin{array}{l}\text { Sample } \\
\text { number }\end{array}$ & $\begin{array}{c}\text { Oil } \\
\text { mark }\end{array}$ & $\begin{array}{l}\text { Sample's } \\
\text { description }\end{array}$ \\
\hline 1 & $\begin{array}{c}\text { Mobil } \\
\text { (used) }\end{array}$ & $\begin{array}{l}\text { Used motor oil } \\
\text { of Mobil(permissible } \\
\text { potential mixing in } \\
\text { the system with oils } \\
\text { of another brand). }\end{array}$ \\
2 & Rimula & $\begin{array}{l}\text { Used motor oil of Shell } \\
\text { (permissible potential } \\
\text { mixing in the system with } \\
\text { oils of another brand) }\end{array}$ \\
\hline
\end{tabular}

The presented samples of unused motor oil were chosen in connection with the fact that the application of oils of $0 \mathrm{~W} 40$ and $10 \mathrm{~W} 40$ grades is optimal in the conditions of the sharply continental climate of the South Kazakhstan region, since keep fluidity in cold weather and when starting the engine, and to a high degree retain its viscosity at high temperatures.

Sample No 3 provides easy engine startup at low temperatures and reliable operation in high-speed modes, including at extremely high temperatures. Viscosity index is 197 . Complies with the API-SJ/CF specification; ACEA-98-A3, B3. Sample No 4 is characterized by good flowability at low temperatures, low volatility, high anti-wear properties due to good heat resistance, lubricating film.

Physicochemical characteristics of unused motor oils samples No. 3 and No. 4 are given in the Table 2.

In the research the concentration of individual aromatic hydrocarbons (benzene, toluene, ethylbenzene and xylene) in the used motor oil was determined by gas chromatography and mass spectroscopy (Table 3).

The results showed that contamination with polyaromatic compounds was not observed in all four samples. Individual aromatic hydrocarbons are found in waste oil samples, however, the level of their concentration was relatively low. Perhaps

Table. 2: Physical-chemical properties of unused motor oil

\begin{tabular}{|c|c|c|c|c|c|c|}
\hline \multirow[t]{2}{*}{ Oil grade } & \multirow[t]{2}{*}{$\begin{array}{c}\text { Classification } \\
\text { SAE }\end{array}$} & \multicolumn{2}{|c|}{$\begin{array}{l}\text { Kinematic viscosity, } \\
\mathrm{mm}^{2} / \mathrm{sec} \text {, at }\end{array}$} & \multirow[t]{2}{*}{$\begin{array}{l}\text { Density, } \\
\mathrm{kg} / \mathrm{m}^{3}\end{array}$} & \multicolumn{2}{|c|}{ Temperature, ${ }^{\circ} \mathrm{C}$} \\
\hline & & $40^{\circ} \mathrm{C}$ & $100^{\circ} \mathrm{C}$ & & & \\
\hline No 3 -Mobil 1 & OW40 & 71 & 13,5 & 865 & $\begin{array}{c}\text { Flash } \\
230\end{array}$ & $\begin{array}{c}\text { Congelation } \\
<-54\end{array}$ \\
\hline $\begin{array}{l}\text { No 4- GTX } \\
5 \text { Lightec }\end{array}$ & $10 W 40$ & 101 & 15 & 875 & 218 & $<-39$ \\
\hline
\end{tabular}

Table .3: The content of aromatic and polyaromatic compounds in the oil samples

\begin{tabular}{lccccccc}
\hline No Sample & \multicolumn{7}{c}{ Content } \\
\hline & Water, \% & Sulfur, \% & Benzene & Toluene & Ethylbenzene & Xylele & PAH \\
1 & 0,05 & 0,3238 & 11,8 & 136 & 116 & 584 & - \\
2 & 3,45 & 0,3442 & 20,3 & 324 & 202 & 635 & - \\
3 & 0 & 0,2897 & - & - & - & - & - \\
4 & 0 & 0,2567 & - & - & - & - & -
\end{tabular}


this is due to the fact that oil samples were taken from the top of the sump. Pollutants tend to settle on the bottom of a storage tank with heavy particles or colloids after some period of inactivity. The same factor can explain the small water content of the used oil.

For subsequent experiments, samples of used engine oil with refined components will be prepared for systematic control of the composition, depending on the influence of various factors, such as ultrasonic exposure and absorption cleaning with vermiculite sorbent. The sonochemical process, the adsorption process and the combined process of destructive adsorption of the samples under the research will be evaluated differentially and the efficiency of the destruction processes will be compared with the goal of developing an optimal scheme for processing used motor oils.

In the process of ultrasonic treatment, which is a sonochemical effect, coagulated asphalt- resinous substances are destroyed to the molecular state separately from the mechanical impurities resinous components. The time of ultrasonic exposure can vary from the mass fraction of mechanical impurities in the spent motor oil.

Further, the activated oil is planned to be directed to the adsorption purification filter. The hardware design of adsorptive treatment of used motor oils includes a complex of equipment and its piping that provides the following technological operations: the supply of sewage to the adsorber, the contact of the oil with the expanded vermiculite sorbent in the adsorber, the separation of the purified oil from the adsorbent and its removal from the adsorption equipment, the withdrawal of the spent adsorbent from adsorber with utilization or regeneration thereof, loading into the adsorber of a clean adsorbent.

Vermiculites are characterized by a high adsorption capacity to absorb oxidation products

Table.4: Physical-chemical properties of used and regenerated motor oil

\begin{tabular}{lcccc}
\hline Charasteristics & \multicolumn{2}{c}{ Used motor oil } & \multicolumn{2}{c}{ Regenerated motor oil } \\
& No1 & No2 & No1 & No2 \\
& & & & \\
& & & & \\
Viscosity, $\mathrm{mm}^{2} / \mathrm{sec}$ & 60,59 & 59,74 & & \\
- at $40^{\circ} \mathrm{C}$ & 9,52 & 9,57 & & \\
- at $100^{\circ} \mathrm{C}$ & 0,087 & 0,072 & 0,016 & 0,023 \\
Mechanical impurities content, \%, no more than & 0,03 & 0,01 & - & - \\
Water content, \%, no more than & 190 & 205 & 205 & 217 \\
Flash temperature, ${ }^{\circ} \mathrm{C}$, no less than & -23 & -22 & -29 & -30 \\
Setting temperature, ${ }^{\circ} \mathrm{C}$, no more than & 880 & 882 & 875 & 877 \\
Density, kg/m ${ }^{3}$, no more than & & & & \\
Content (ppm): & 0,3139 & 0,3443 & 0,2432 & 0,2156 \\
- sulfur; & 23,4 & 12,8 & - & - \\
- benzene; & 406 & 307 & - & - \\
- toluene; & 823 & 594 & - & - \\
- xylene; & 11,8 & 7,8 & - & - \\
- polyaromatic hydrocarbons. & & & & \\
Content (ppm): & 21,16 & 10,69 & 0,98 & 0,89 \\
- (Pb); & 402,96 & 387,56 & 140,99 & 138,25 \\
- (Zn); & 57,94 & 41,36 & 12,65 & 11,03 \\
- (Al); & 171,94 & 203,12 & 67,54 & 63,41 \\
- (Ca); & 436,12 & 440,96 & 124,36 & 122,15 \\
- (Mg); & 37,85 & 32,48 & 3,54 & 3,03 \\
- (Cu); & 18,26 & 7,95 & 5,89 & 2,18 \\
- (Cr). & & & & \\
\hline
\end{tabular}


of hydrocarbons - resins, oxygen and other heteroorganic compounds. It is recommended to use activated vermiculite, because under the activation, a significant portion of the magnesium, iron, and aluminum oxides dissolve, and the $\mathrm{SiO}_{2}$ content in the samples is increased, which leads to an increase in the absorptivity.

Based on the dispersed composition of the adsorbent (vermiculite) and the filtering charge, the principal design of adsorption device with fixed loading through which the oil flow is filtered downstream at a speed of up to $10 \mathrm{~m} / \mathrm{h}$ was chosen.

The data obtained as a result of complex processing of used engine oils show that the method provides an efficient regeneration of the oil, a decrease in the content of metals, aromatic and polyaromatic hydrocarbons in the composition of the oil (Table 4), as well as adsorptive post-cleaning with vermiculite sorbent, significantly reduces the content of mechanical impurities and water.

The combined adsorber filter is easily regenerated by water heated to $60^{\circ} \mathrm{C}$, and vermiculite does not lose its properties after multiple "purification-regeneration" cycles.

The method of regeneration of used motor oils by ultrasonic treatment in conditions of dispersing asphalt-resinous compounds with subsequent purification by vermiculite sorbent is universal. It is applicable for various grades of oils, and also provides an effective regeneration of oil on environmentally friendly, non-energy-intensive and low-cost technology.

\section{CONCLUSION}

Estimated practical significance of the work lies in the possibility of using developed complex technology for used motor oil purification, implemented under mild conditions with the use of ultrasonic irradiation and adsorption methods to regenerate oil complying with the current environmental requirements. The proposed technology will facilitate the development of new areas of application of known adsorption-catalytic materials, which is especially important for domestic producers in a high competition with imported products.

The results presented in this article was obtained in the framework of implementation of the project of the Ministry of Education and Science of the Republic of Kazakhstan No 0993/GF4 "Production technology development of polyfunctional sorbents for quality improving characteristics of oil, oil products and waste waters".

\section{ACKNOWLEDGEMENTS}

The results presented in this article was obtained in the framework of implementation of the project of the Ministry of Education and Science of the Republic of Kazakhstan No 0993/GF4 "Production technology development of plyfunctional sorbents for quality improving Characteristices of oil, oil products and waste waters".

\section{REFERENCES}

1. Gallup, Darrell L.Reducing the Leachable Lead Content of Used Oil Filter Paper. Environ. Prog. 1996, 62-68.

2. Fendler, J.H. Membrane Mimetic Chemistry. 1998, 256

3. Fang, C.S.; P.M.C. Lai. Journal of Microwave Power \& Electromagnetic Energy, 1995, 46-57

4. Hong; Qi, Joanna L.; Hardcastle, Ross A. Sonochemical Degradation of Trace Cyanide and Dye Stuffs in Aqueous Media. New J. Chem. 2006, 845-849

5. Douglas S.; Stanley D. Schoenwald. The Determination of Sulfur and Chlorine in Used Oil by X-ray Fluorescence, ICP and Ion Chromatography. Hazardous Waste \&
Hazardous Materials. 2012, 373-380

6. Kotronarou, A.; G. Mills. Oxidation of Hydrogen Sulfide in Aqueous Solution by Ultrasonic Irradiation. Environ. Sci. Technol. 2003, 2420-2428

7. Oil \& Gas J.; Editing Board. Depoisoning Process Turns Used Oil into Valuable Feed. Oil. Gas. J. 1997, 95, 61

8. Peaslee, Kent D. Recycling Used Automotive Oil Filters. JOM, 1994, 46, 44-46

9. Peaslee, Kent D. Researcher Targets Recycling of Oil Filters. Advanced Materials \& Processes. 1995, 148, 6.

10. Mason, T.J. Industrial Sonochemistry: Potential and Practicality. Ultrasonics. 1992, 30(3), 192-196. 